\title{
Amino-terminal processing of proteins
}

\author{
A. Ben-Bassat and K. Bauer
}

Recombinant proteins produced in bacteria often retain the initiation methionine at their amino-terminal
end. This N-terminal methionine may affect the immunogenicity of the protein, necessitating removal.

Protein synthesis is always initiated with either methionine in eukaryotes or $N$ formylmethionine in prokaryotes and eukaryotic organelles. The $N$-formyl moiety present in the proteins of eukaryotic organelles and bacteria is normally removed by deformylase, leaving methionine at the $\mathrm{N}$-terminus. In the production of many intracellular proteins the methionine is removed by methionine aminopeptidase (MAP) after the initiation of translation. The substrate specificity and universality of MAP among prokaryotes and eukaryotes has been inferred from the $\mathrm{N}$-terminal sequence analysis of mature cytosolic proteins ${ }^{1,2}$. Recently the substrate specificity of MAP was verified using enzyme from Escherichia coli. ${ }^{3}$

\section{Influential neighbours}

Methionine cleavage from the $\mathrm{N}$-terminal end of the protein is strongly affected by the adjacent amino-acid residue. When the side chain of this penultimate amino acid is large, hydrophobic or positively charged, the methionine is retained; when the side chain is small and uncharged the methionine is cleaved (Table 1). Consequently, the DNA sequence of a gene can be used to predict the fate of the $\mathrm{N}$ terminal methionine of the resulting protein. These conclusions are based in part on qualitative sequence analysis of endogenous cytosolic proteins ${ }^{1,2}$; partial removal of the methionine may be counted as a non-cleavage event. Partial processing of methionine can happen, especially when the penultimate amino acid is Ile, Val, Cys, or another amino acid of intermediate size.

Although no similar studies have been conducted with recombinant proteins, it is reasonable to assume that similar rules apply to their processing. Our experience with recombinant protein expression generally supports the conclusions obtained from endogenous cytosolic proteins. In addition, we found that other factors besides the penultimate residue affect the cleavage of methionine and that the cleavage of the methionine from hyperproduced recombinant proteins is frequently incomplete ${ }^{3}$.

Many of the recombinant proteins that are produced for therapeutic uses are based on secretory products from mammalian cells. The $\mathrm{N}$-terminal signal peptides in these secretory precursors are cleaved during the translocation process; thus the mature proteins do not normally contain methionine at the $\mathrm{N}$-terminal end. Examples are $\gamma$-interferon (Gln-Asp-), tumour necrosis factor (Val-Arg-Ser-),
and human growth hormone (Phe-Pro-). Production of these proteins in $E$. coli intracellularly often results in a product with an extra methionine. Obviously, the biotechnology industry has a strong interest in removing this methionine in order to avoid potential immunogenicity problems, and to obtain a more homogeneous product, without incompletely processed molecules.

Several methods have been used to remove the extra methionine. This first is removal of the methionine by treatment with cyanogen bromide ${ }^{4}$. This method involves chemical modification and requires extra preparation steps. It is not $\mathrm{N}$ -

Table 1 Cleavage of $\mathrm{N}$-terminal methionine in intracellular prokaryotic proteins.

\begin{tabular}{|c|c|c|}
\hline $\begin{array}{c}\text { Met } \\
\text { cleaved } \\
\text { Ala } \\
\text { Gly } \\
\text { Pro } \\
\text { Ser } \\
\text { Thr }\end{array}$ & $\begin{array}{c}\text { Met removal } \\
\text { varied } \\
\text { Cys } \\
\text { His } \\
\text { Met } \\
\text { Trp } \\
\text { Tyr } \\
\text { Asp } \\
\text { Glu } \\
\text { Gln } \\
\text { Val }\end{array}$ & $\begin{array}{c}\text { Met } \\
\text { retained } \\
\text { Lys } \\
\text { Arg } \\
\text { Leu } \\
\text { Ile } \\
\text { Asn } \\
\text { Phe }\end{array}$ \\
\hline
\end{tabular}

The data show the effect of the penultimate amino acid on methionine removal ${ }^{2}$.

terminal specific, and therefore its application is limited to proteins lacking internal methionines.

Fusion of the coding sequence of the recombinant protein with a sequence coding for a signal secretory peptide is another method ${ }^{5}$. In this procedure, the fused protein is secreted through the cytoplasmic membrane and cleaved at the fusion site by a signal peptidase. The recombinant protein can then accumulate in the periplasmic space in Gram-negative bacteria or in the growth medium in yeast and Gram-positive bacteria. Unfortunately, secretion of mammalian cell products in prokaryotes and yeast is often limited.

Enzymatic removal of the N-terminal methionine with aminopeptidase has also been used ${ }^{6}$. Here the methionine is removed by incubating the recombinant protein with a peptidase from Aeromonas proteolytica. This enzyme is a nonspecific aminopeptidase that cleaves amino acids sequentially from the $\mathrm{N}$-terminal end of proteins. The stop signals for the enzyme are Glu, Asp and $x$-Pro, where $x$ can be any amino acid except proline ${ }^{6,7}$. This is suitable for removing $\mathrm{N}$-terminal methionine when a stop signal is close to the methionine. The initiation methionine in $\gamma$-interferon (Met-Glu-Pro-) and bovine growth hormone (Met-Asp-Glu-) have been removed using this enzyme. When the stop signals are not near methionine, proteolysis by this enzyme can continue, digesting the rest of the protein until it encounters a stop signal. Examples are human growth hormone analogue (MetLys-Val-Glu-), where methionine, lysine and valine are removed ${ }^{6}$.

\section{The latest advance}

The most recent development in $\mathrm{N}$ terminal processing is the in vivo and in vitro removal of the $\mathrm{N}$-terminal methionine using the MAP enzyme ${ }^{3}$. The MAP gene was recently isolated, cloned and overexpressed in $E$. coli by the authors and their coworkers. The in vivo method involves expression of the recombinant protein in a MAP-hyperproducing $E$. coli host. The advantage of this method is that it does not require additional purification steps for both recombinant protein and MAP. The in vitro method consists of incubating the purified recombinant protein product with purified MAP. The peptidase can be purified easily from hyperproducing $E$. coli strains, that express MAP at proportions of up to 20 per cent of total cell protein. The utility of these methods was demonstrated by the removal of methionine from interleukin-2 (Met-AlaPro-) and ricin A (Met-Ile-Phe-) both in vivo and in vitro. Recombinant proteins are normally exposed to the native activity of MAP in wild-type cells, but this low concentration often results in incomplete processing. Using an $E$. coli strain with extra MAP-bearing plasmids for the in vivo method increases the level of MAP in the cell, assuring more complete cleavage of the N-terminal methionine. In the in vitro method, proteins are incubated with a high concentration of enzyme, and the length of incubation can be adjusted to accomplish complete processing.

Arie Ben-Bassat and Keith Bauer are at the Department of Fermentation $R \& D$, Cetus Corporation, Emeryville, California 94608, USA. For more information fill in Reader Service No. 100.

\footnotetext{
Sherman, F. Stewart, J.W. \& Tsunasawa, S. BioEssays 3 27-31 (1985).

2. Flinta, C., Persson, B., Jornvall, H. \& von Heijne, G. Eur. J. Biochem. 154, 193-196 (1986)

3. Ben-Bassat, A. et al. J. Bact. 169, $751-757$ (1987)

4. Harris, T.S.R. Genet. Engng 4, 127-185 (1983).

. Kohr, W.J., Keck, R. \& Harkins, R.W. Analyt. Biochem. 122, 348-351 (1982).

6. Blumberg, S. \& Ben-Meir, D. (inventors) Bio-Technology General Corp. (applicant), International Publication Number W086/01229 (World Intellectual Property Organisation 1986)

7. Prescott, J.M. \& Wilkes, S.H. Meth. Enzym. 44, 530-543
} (1976) 